\title{
A Arte nas aventuras da Interpretação
}

\author{
Anta Prado Koneski
}

Dentre as inúmeras possibilidades interpretativas que a arte nos oferece, apresento nesta exposição o viés proporcionado pelo pensamento de Bachelard. Como resultado da inversão entre o real e o irreal, surge uma reflexão a respeito da prática do Educador em Arte

O título da presente exposição está pautada no fato de que esta proposta faz parte de uma das inúmeras possibilidades para pensarmos a arte. Este, portanto, é um dos viesses possíveis de interpretação da arte. É importante lembrar que esta escolha passa por uma postura diante da arte, enquanto pessoa, professora e, até mesmo, numa visão mais ampla, de compreensão da vida e do mundo.

Bachelard no seu texto, A Poética do Espaço, dá ao irreal o estatuto de real e com isso inverte o nosso olhar para o mundo, através da imaginação poética. É um convite para que façamos com que o irreal seja tão útil quanto o real. É na verdade um convite para que o irreal deixe de ser tratado como o contrário do real. Eu, particularmente diria, que Bachelard nos recorda o direito adquirido de sonhar "sonhos diurnos", onde temos plena consciência do sonhado, de transitarmos pela instabilidade e de darmos à imaginação o estatuto de veracidade. Em Bachelard, temos a imaginação deslocada do peso da estabilidade da razão explicativa, instituindo a positividade da instabilidade.

Para o filósofo a arte se apresenta como um modelo "alternativo" para a racionalidade 
O primeiro passo para esta abordagem seria , então, convocá-los a crer no irreal, e conduzi-los a perceber que este irreal, inúmeras vezes é mais real que o próprio real, porque caminha pelas aventuras da interpretação e da singularidade dos olhares que o intenciona.

A questão que levantamos aqui, pautada na escolha pelo pensamento bachelariano, refere-se a um problema que transita na reflexão da oposição entre Mito/Logos. Estamos habituados a pensar que o logos é o especificamente humano no homem.

Por muito tempo na história do conhecimento humano foi dado acreditar que só a razão podia dizer a realidade à nossa volta. O mito, o irreal, a fantasia estava no âmbito da irracionalidade e não poderia ser fonte de conhecimento. De outro lado, nos parece que este tempo não tenha ficado para trás em definitivo ao depararmos, não poucas vezes, com a desvalorização da arte perante as outras formas de conhecimento, pelo seu teor "irreal".

Esta tradição de pensamento que institui a razão como única via para o conhecimento vem de muito longe. Vamos fazer um breve passeio no passado. Podemos relembrar o responsável por ela: Platão. A arte foi por este filósofo pouco recomendável na polis grega por seu caráter de irracionalidade. Depois de Platão temos essa idéia reforçada pela llustração que depositou excesso de confiança no progresso da cultura sob o domínio da razão.

O mito sempre fora tomado como uma explicação
irracional do mundo, e portanto, com pouca validade. A maneira como a ciência da tradição interpretava o mundo anulava a imagem mítica, sendo que, atestavase como mitológico o que não pudesse ser submetido ao método científico. 
O pensamento romântico vai ser o primeiro a fazer uma crítica à fé na razão. O romantismo vai se revelar na conquista do pensamento que afirma o fato de que jamais obteremos a verdadeira ordem das coisas, como pede o pensamento da razão formulado como fonte absoluta do conhecimento.

A razão estabelecida como império do mundo, no âmbito teórico, faz da natureza o que ela quer. Institui a natureza a partir de si. A tecnologia, por exemplo, força a natureza a assumir uma forma previamente concebida. Não permite que a natureza diga o que ela quer, fabricando o experimento a fim de que este responda ao que ela procura.

Segundo Gadamer (1997), há uma forte correspondência entre a experiência que a arte faz com o mundo e a experiência mítica, abrindo desta forma, um caminho amplo para a reflexão dentro dessa abordagem, onde a experiência poética vê o mundo miticamente. Como a arte, o mito tem uma verdade que é própria, inalcansável pela explicação racional do mundo. Como no mito, a arte tem sua verdade situada num tempo originário. Trata-se de uma ida ao mundo não para explicá-lo, mas para apreendê-lo e, ouvir o que ele tem a nos dizer. A arte faz uma leitura do mundo que se apresenta transfigurada, o que chamamos de "irreal", torna-se fecundidade no "real".

O que estamos tentando expor é que a oposição entre a razão e a imaginação poética não é pertinente, tratando-se apenas de uma aparente oposição, fortalecida nos âmbitos da história do pensamento humano. A arte é uma forma de conhecer o mundo tão fecunda quanto a ciência. A arte é outra forma de dizer uma mesma realidade. Digamos que é uma questão de estrutura e que a arte faz sua experiência de verdade por outra via de racionalidade.

Em relação a razão explicativa a arte possui, no seu modo de abordar o mundo, 
razões que a razão científica desconhece. A arte abre novas vias de penetração na realidade, constrói formas que Ihes são próprias e diferenciadas de ir à realidade. A imaginação, mentora da arte, na sua ida à realidade não carrega medidas, análises e sistematizações, mas abre-se para um conceito de relação originária.

A relação da razão científica com o mundo também é relacional, porém a arte, abre uma interatividade lúdica com o mundo a sua volta, que the é peculiar. É nesta peculiaridade de jogo lúdico que acontece a transfiguração do instituído, e o mundo se reverte no irreal, que faz ecos profundos na nossa existência. A experiência em arte pensada da maneira como estamos propondo desconhece o esquema sujeito/objeto, autonomia/heteronomia, corpo/mente, espaço/tempo, passado/presente, eterno/novo. As relações sugeridas pela arte faz questão do envolvimento, da vivência, da aceitação das inúmeras possibilidades de leituras que o mundo a nossa volta oferece pela via da imaginação criadora, num resultado especificamente seu, que é a estrutura do irreal. Há sempre um grande mistério a ser descoberto nos âmbitos relacionais criados.

Assim, tanto quanto a razão científica a imaginação poética também dá respostas ao mundo que habitamos. A arte funda um conhecimento e uma verdade, sendo que suas respostas são dadas em estruturas artísticas onde, o irreal reveste-se de real. Desta forma, o que a arte plasma não são objetos mas realidades relacionais (Quintás1998:477). A arte não quer dizer a verdade da realidade objetiva que nos circunda, dessa realidade mensurável, delimitada, mas a vertente relacional entre existência e realidade.

A racionalidade que é específica da arte se desenvolve no espaço criativo, resultado de nossas 
relações com o mundo. A coisa, mero objeto, na relação de jogo lúdico se converte em lugar de interação - em símbolo. O movimento do corpo, que se envolve no jogo, se transforma em gesto, um movimento significativo. Instaura-se uma relação de presença, o gesto torna-se ritual e tudo se eleva a nível de cultura. A cultura, para Quintás (1998:480), é o real elevado a um nível de transfiguração e intercomunicação. É assim, que podemos dizer que, o que escapa ao conceitual da análise, da sistematização, fica clarificado na arte.

A obra de arte resulta desse jogo inter-relacional com o mundo, transformando-se em um símbolo polisêmico permitindo inúmeras formas de interpretação. Assim, uma obra de arte é sempre inesgotável na sua abertura às interpretações. É nesse sentido que ela é sempre presença, atualidade, novidade, unidade do eterno e do novo, na abordagem do mundo. Nela nada é estável, fixo, a mutabilidade constante faz com que sua verdade esteja situada no seu acontecer enquanto interpretabilidade.

Na absorção do mundo a nossa volta, os braços desesperadamente erguidos da mãe que segura o filho, na obra Guernica, de Picasso, abrem para um campo relacional dificilmente captado pela ciência. O campo aberto é de outra ordem, escapa aos conceitos. Isso porque a arte não se oferece como uma utilidade objetiva à nossa razão utilitária, mas se oferece como abertura do que o objeto utilitário é na sua essência. A obra nos dá a dimensão humana que permeia as coisas na realidade. Nos diria Heidegger (1999:27), isso porque, "a obra de arte põe em obra a verdade do ente", e desta maneira nos mantém abertos para outro tipo de relação com as coisas a nossa volta. Esta abertura implica galgarmos caminhos nada seguros e absolutizados, porque ficam suspensos ao fazer comum.

A instauração do simbólico, do mito, do irreal, da fantasia, expande para o campo da existência por um 
viés onde os conceitos não dão conta da multiplicidade de faces com que o Ser se apresenta. Isto porque, o Ser na arte fala muito mais pelas vias da alma do que pelas vias do espírito, ou seja, muito mais pelas emoçōes do que pela razão explicativa.

A forma de conhecimento veiculada na arte é a da "ação", da interpretação, que se dá na inter-relação singular que cada um de nós mantemos com a obra. Nela estão âmbitos de nossa existência humana que adquirem um corpo concreto. Daí nos reconhecermos nela. Bachelard diz a respeito da leitura, "todo leitor que relê uma obra que ama sabe que as páginas amadas the dizem respeito" (Bachelard, 1993:10). É desta maneira que cada um vai apalpando, acolhendo, inventando as vias de diálogo com a obra, captando-Ihe o significado e confirmando-o na sua própria experiência, através de um certo modo de habitar o mundo somente seu.

A experiência artística tem por tarefa dar concreticidade à relações entre o sujeito e o mundo a sua volta, através de uma modo peculiar de se fazer obra. Ela tem uma concepção lúdico-relacional.

Diante de tais questões quais as propostas que poderíamos tirar daqui para o ensino da arte e de nossas próprias relações, enquanto professores, com a arte.

A primeira, eu diria, seria reforçarmos esta paixão pelo irreal, que muitos professores, educadores em arte ainda não tem. Esta paixão que crê no estatuto ontológico de irreal. Este, sem dúvida, seria o primeiro passo. Não há qualquer tipo de ensino, sem vivência, sem envolvimento, sem a crença, no sentido que aqui
propomos.

Depois poderíamos pontuar outras questões resultante desta fala. Talvez pudéssemos chamar de conclusões provisórias. 
A experiência artística nos instiga a uma a relação de alteridade, no sentido de que desdobra as relações sujeito/objeto, as pretensões a verdades absolutas, a um olhar fixo para o mundo. Nos abre outra possibilidade de conhecimento, no sentido de que mostra a mutabilidade do mundo, e a instabilidade das verdades estabelecidas. Esta rebeldia salutar e louvável, inerente à arte trabalha em nós uma reflexão sobre o mundo muito ampla no âmbito existencial, nos entrega a visão de outra dimensão da existência. Transforma todo espaço em espaço poético, na reversão do espaço da objetividade.

A verdade conforme interpretamos a experiência artística não está dada a priori, mas tem seu lugar como acontecimento. Infundimos relevância à interpretação. A interpretação que se apropria da obra enquanto vivência íntima, onde a consciência que analisa, sistematiza e fragmenta não é o principal instrumento. Nesta interpretação não existe a supremacia do sujeito sobre o objeto, mas o entrelaçamento de experiências. Só dessa maneira podemos dizer que a obra de arte é fecundidade dentro de nosso espaço existencial. Quando sua presença nos põe em relação com o mundo, aciona nossa participação instigando respostas. A experiência em arte mostra, alerta, denuncia, revela, brinca, são maneiras de tornar evidente um universo que se coloca dentro de um âmbito que descarta a verificabilidade, porque usa os instrumentos personalizados para aproximar-se de cada um de nós. É inerente à experiência artística a alteridade, o diálogo. Particularmente penso, que se como educadores não acreditarmos nisso, se não trabalharmos para que esta proposta se realize, seremos meros repassadores de conhecimentos em arte. Com certeza estas questões implicariam uma longa conversa.

Deduzimos que toda obra de arte é aberta ao diálogo. O contato interpretativo da obra acolhe um 
conhecimento ativo e pessoal, seu movimento implica numa conquista própria e original. Deduzimos também que provavelmente o mais viável seria que o ensino da arte pudesse tirar daí sua postura. Pensando em questões como: ausência de regras prontas, conquista original, pessoal, relação de crença com o irreal em questão, ter prazer de envolver-se com a instabilidade constante, e tantas outras, que podem construir uma postura de educador em arte, pelo menos do educador que nos propomos pensar aqui.

A questão do diálogo proposto com a obra está aqui pensado no sentido de troca, onde a obra se revela e o sujeito se exprime. A interpretação é adequação de descoberta com afinidade, visão com sintonia.

Por fim podemos lembrar que a arte está aberta à revelação. Para tanto é necessário que tenhamos o desejo e a curiosidade de entrarmos em experiência relacional com ela. Só podemos entendê-la como um objeto que transita em nosso meio com vocação interativa. É uma forma-viva, que vive em nosso meio concreto e no nosso entendimento. Esta interatividade e comunicabilidade é construída não na contemplação pacífica, mas em movimento, no devir constante das relações de presença. Isso significa que a arte está mesmo, e de muito bom grado, sujeita as aventuras da interpretação.

Partindo desta postura queremos pontuar, que não existe um centro único para a interpretação, e a partir daí o que se instala é um "olhar" de respeito ao diferente, sugestão de acolhimento à alteridade, transformando em fecundidade poética todo espaço objetivo.

A partir desta abordagem do mundo, na qual a arte se integra, talvez possamos pensar, ou repensar, um novo conceito de liberdade, que perneie o pensamento nas raias da "debilidade", na ausência de 
absolutos, em espaços mais variacionais e menos constitutivos.

Provavelmente estejamos necessitados não tanto das asas de ĺcaro, asas da racionalidade pura, mas das asas de Mercúrio, pequenina nos pés, imagem de uma realidade onírica, porque como nos diz Bachelard, o vôo onírico não é alado.

Melhor é lembrarmos, que no mundo dos sonhos não se voa porque se tem asas, mas se crê nas asas porque se tem voado. (Bachelard, 1993:40) Talvez tenhamos que terminar como iniciamos: reforçando a crença no irreal.

\section{Referências Bibliográficas}

BACHELARD, Gaston. A Poética dos Devaneios. São Paulo: Martins Fontes, 1993. Fontes, 1993.

. A Poética do Espaço. São Paulo: Martins

. El Aire y los Suenõs. Mexico: Fondo de Cultura Económica, 1993.

GADAMER, Hans G. Verdade e Método. São Paulo: Vozes, 1997. . Mito y Razón. Barcelona: Paidós, 1997.

HEIDEGGER, Martin. A Origem da Obra de Arte. Rio: Edições 70, 1990.

PAREYSON, Luigi. Estética Teoria da Formatividade. São Paulo: Vozes, 1993.

VATTIMO, Gianni. O Fim da Modernidade. São Paulo: Martins Fontes, 1996.

- Para Além da Interpretação. Rio : Tempo Brasileiro, 1999. 